\title{
Development of Epithelial Attachment and Gingival Sulcus in Rhesus Monkeys
}

\author{
BY W. O. ENGLER,* S. P. RAMFJORD,* AND J. J. HINIKER**
}

$\mathrm{T}$ HE purpose of this investigation was to utilize tritiated thymidine to study the origin and behavior of the cells that make up the epithelial attachment and line the gingival sulcus.

The first line of defense against periodontal disease is the epithelial seal between the tooth and the gingiva. During the last decade, the concept of a dynamic ${ }^{1}$ rather than an organic epithelial attachment ${ }^{2}$ has gained in acceptance. ${ }^{3,4,5,6,7,8,9}$ However, a group of investigators (mainly British) have suggested that the reduced enamel epithelium that makes up the original epithelial attachment may remain both as an unsuitable covering of the gingival sulcus and provide an inferior epithelial attachment for many years. ${ }^{10,11,12}$

The advent of tritiated thymidine has provided a vastly improved technique to record the proliferative potential of the cells which constitute the junction between the tooth and the gingiva. Tritiated thymidine radioautography is based on the incorporation of a labeling isotope, tritium, into the deoxyribonucleic acid (DNA) of the nuclei of cells preparing for mitosis. Although thymidine is not a normal precursor of DNA it enters the cell, possibly by phosphorylation to thymidilic acid, ${ }^{13}$ and is incorporated into deoxypolynucleotide in a diester linkage indistinguishable from the linkage of the natural precursor of DNA. ${ }^{14}$ The reliability of the tritiated thymidine technique is based on several assumptions (listed by Cronkite et al. ${ }^{15}$ 1959) such as: 1 . The tritium label on thymidine does not exchange, and the thy-

*School of Dentistry, The University of Michigan, Ann Arbox, Michigan.

$\because$ Veterans Administration Hospital, Ann Arbor, Michigan. midine is not exchanged af ter incorporation in DNA. 2. DNA turnover is solely the result of cell mitosis or death.

Although it has been reported that under certain circumstances tritiated thymidine has been found incorporated into differentiating cells $s^{16,17,18}$ (such as ameloblasts ${ }^{17}$ ) which subsequently failed to undergo mitosis, it is accepted as a general principle that cells synthesizing DNA and incorporating tritiated thymidine are about to enter the mitotic cycle. This latter assumption has been the basis for the conclusions presented in several recent publications concerning the use of tritiated thymidine for study of periodontal tissues, $4,5,6,7,8,19$ and it was accepted in a general way as the basis for the present investigation.

\section{MATERIAL AND METHOD}

A female rhesus monkey carrying a four month fetus, a four and one-half month baby rhesus monkey, and an adult rhesus monkey were used for the present investigation. The adult monkeys received by intravenous injection, a dosage of 1 microcurie of tritiated thymidine (specific activity 6.7 curies per millimole*) per gram of body weight. The baby monkey was given a similar dosage by intraperitoneal route. The animals were sacrificed about 1 hour and 15 minutes after the injection.

The jaws with the teeth and head of the fetus (removed at the time of the necropsy of the mother) were fixed in $10 \%$ neutral buffered formalin for three weeks, divided in to small specimens and decalcified in $20 \%$ ethylenediamine tetraacetic acid (EDTA) adjusted to a $\mathrm{pH}$ of 7.4 with sodium hydroxide.

NNew England Nuclear Corporation, Boston, Massachusetts. 


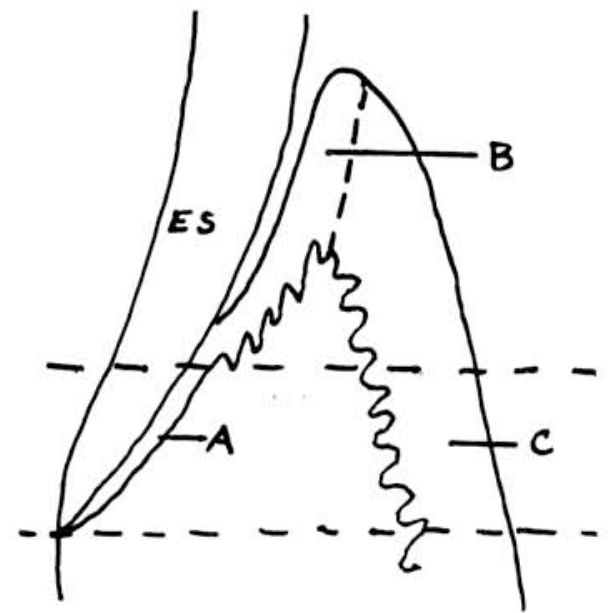

Fig. 1. A diagram of the gingival margin demonstrating the divisions of the epithelium made to facilitate counting. (A) epithelial attachment, (B) coronal suleus epithelium, (C) gingival surface epithelium, (ES) enamel space.

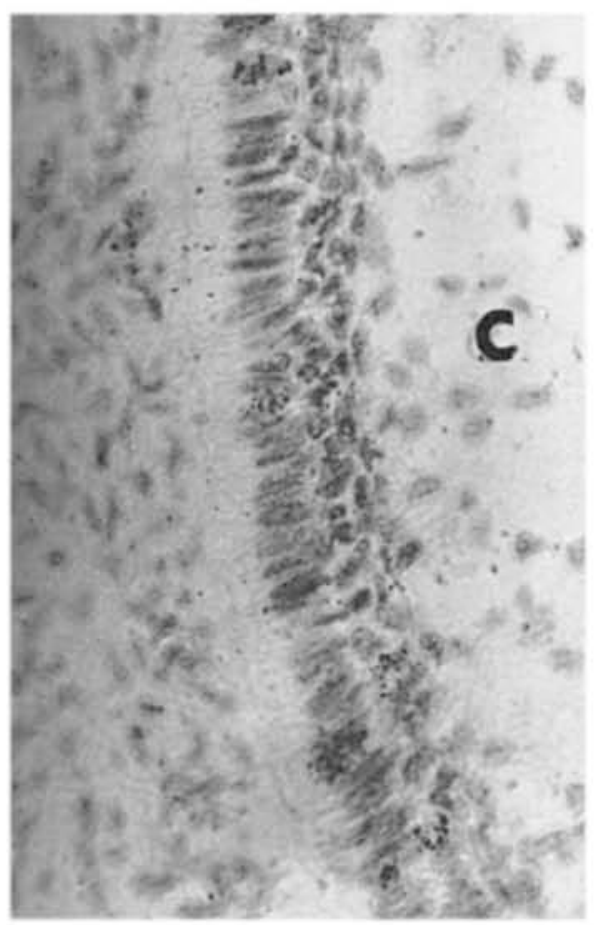

Fig. 2. Labeled preameloblasts and stratum intermedium cells of enamel organ, (C) stellate
reticulum, baby monkey. (Magnification X464.)
Following decalcification, the specimens were washed in running water overnight, embedded in paraffin, and sectioned at 8 microns. The sections were mounted on gelatin treated slides, placed on a hot plate at $40^{\circ} \mathrm{C}$ overnight and deparaffinized.

Radioautographs were then prepared using a modification of the dipping technique presented by Messier and Leblond ${ }^{20}$ and Joftes. ${ }^{21}$ Nuclear Track Beta Emulsion (NTB-3)* was diluted 5 to 1 with distilled water and heated at $49^{\circ} \mathrm{C}$ to facilitate the dipping. Following vertical drying, the slides were stored for exposure in light tight boxes with $\mathrm{KNO}_{2}$ to produce a constant humidity of approximately $47 \%$ and the temperature was kept at $4^{\circ} \mathrm{C}$. By pilot studies it was found that three weeks of exposure produced a clear radioautograph with minimum background. At the end of the exposure, the slides were developed, fixed, stained with Ehrlich's acid hemotoxylin, and mounted with Parmount.

Radioautographs were made of approximately 1,100 slides, each containing four to eight tissue sections, thus providing for the study about 6,000 radioautographs with sections of teeth and surrounding tissues in various stages of development.

The gingival epithelium was divided into three zones as suggested by Dimassimo ${ }^{8}$ for study and counting of cells (Fig. 1). Zone A includes what usually is referred to histologically as the epithelial attachment, while zone $\mathrm{B}$ extends coronally from the epithelial attachment to the free gingival margin. These two zones can be separated readily by morphologic differences. The epithelial attachment (A) is thin and has a regular basal cell boundary while the coronal part of the sulcus epithelium is much thicker and has an irregular basal cell boundary. Zone $\mathrm{C}$ comprises the area of gingival surface epithelium opposite zone A in the sulcus.

"Eastman Kodak Company, Rochester, New York. 
Forty-two areas of fetal oral epithelium and of zones $\mathrm{A}, \mathrm{B}$, and $\mathrm{C}$ of teeth from the baby and adult monkeys were selected at random and counted using the method of Messier and Leblond. ${ }^{22}$ The total labeled and unlabeled nuclei in contiguous squares were counted, using a hand tally counter, and viewing the slides over oil emersion $(1000 \mathrm{X})$ with the field outlined by a Howard disk in the ocular. The radioactivity index for each zone was determined by the ratio between the number of cells labeled to the total number of epithelial cells in the area counted and expressed in percentage.

\section{FINDINGS}

A. The Fetus and the Baby Monkey. Only findings related to the enamel organ after initiation of amelogenesis and the subsequent stages through eruption and formation of the adult gingival crevice are reported in this paper. Observations made with regard to initiation and early morphogenic states are to be reported in a separate paper. ${ }^{23}$ The second deciduous molars and all of the permanent teeth were unerupted in the baby monkey.

In no instances were functioning ameloblasts labeled; however, as indicated by previous investigators, ${ }^{4,17,24}$ preameloblasts were occasionally labeled (Fig. 2). Cells of the outer enamel epithelium and stratum intermedium exhibited labeling in all stages of amelogenesis, while no labeling was observed in the stellate reticulum.

Following amelogenesis, the reduced enamel epithelium was composed of residual cells of the enamel organ. The inner layer of cells contacting the enamel were columnar with centrally located nuclei, none of these cells were labeled. The outer layer of the reduced enamel epithelium was derived from the cells of the outer enamel epithelium and the stratum intermedium and consisted of loosely arranged polygonal cells separated by amorphic homogenous material. Occasionally, a labeled cell could be observed in the outer layer of the reduced enamel epithelium while the tooth still re-

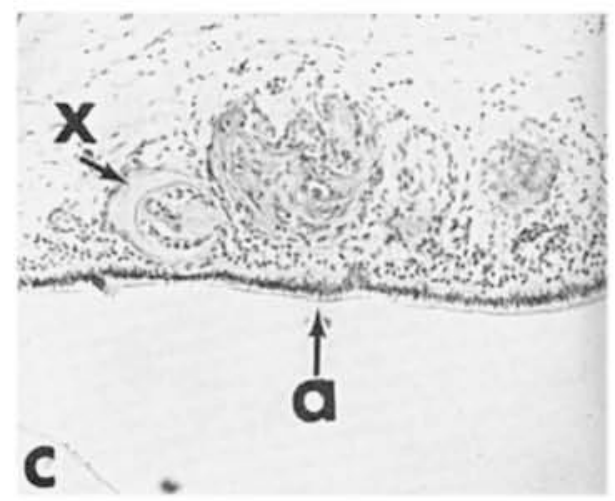

Fig. 3. Outer and inner layers of reduced enamel epithelium covering unerupted crown, baby monameloblasts, (C) dentin. (Magnification X81.)

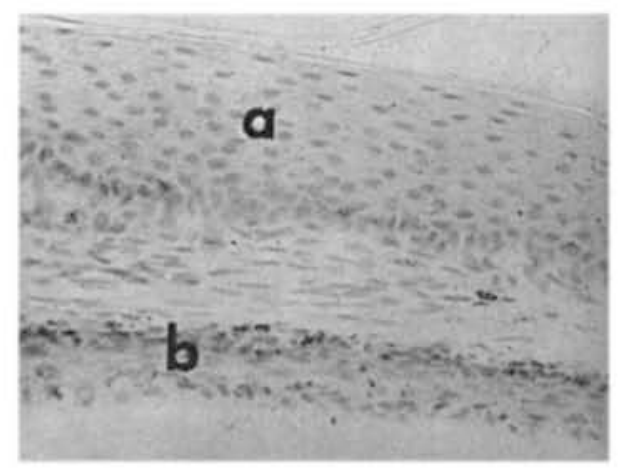

Fig. 4. Oral (a) and reduced enamel epithelium (b) just prior to fusion over eruptiny cusp tip. baby monkey. Labeled cells in basal layers of tion $\mathrm{X} 290$.)

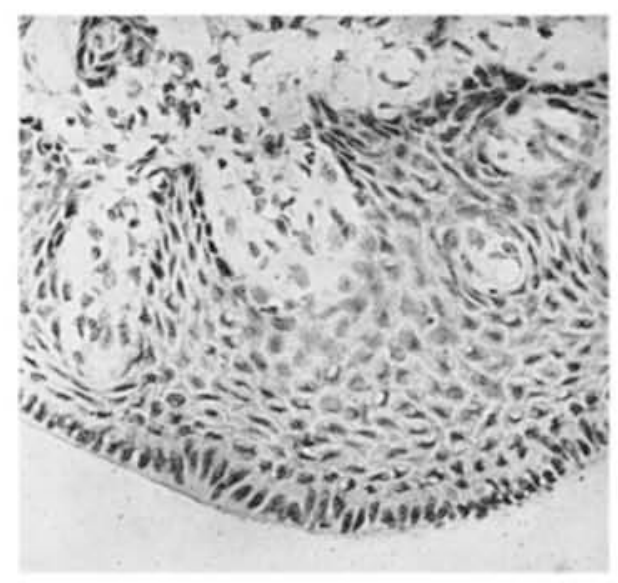

Fig. 5. Reduced enamel epithelium covering central fossa of erupting tooth, baby monkey. Labeled cells in proliferating outer layer of reduced enamel epithelium. (Magnification X330.) 


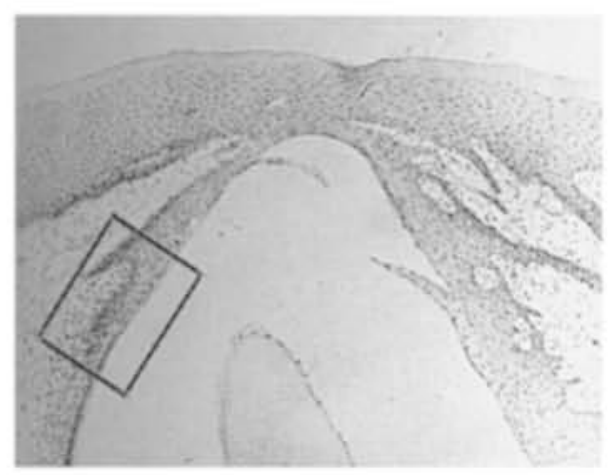

Fig. 6A. Fusion of oral and reduced enamel epithelium over erupting cusp tip, baby monkey. Labeled cells in basal layer of oral epithelium and surface of rednced enamel epithelium. (Magnification X94.)

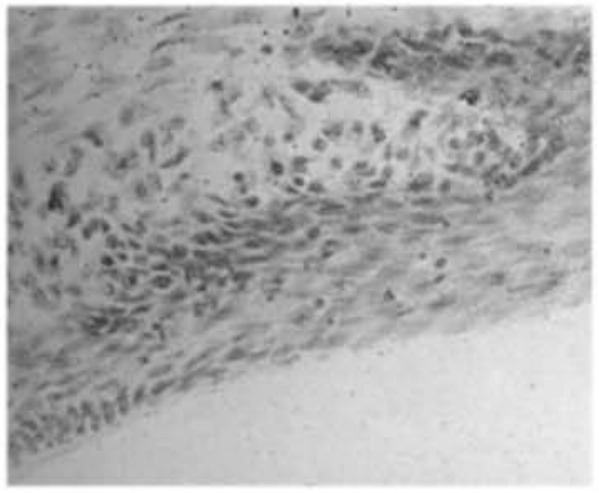

Fig. 6B. Higher magnification of square from Fig. 6A. Labeled cells in epithelial downgrowth. (Magnification $\mathrm{X} 440$.)

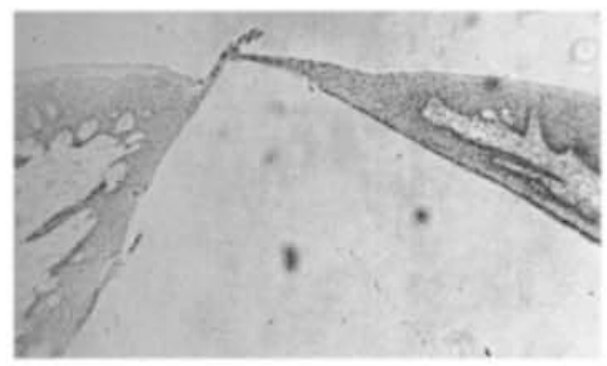

Fig. 7. Rupture of fused epithelial layer over an erupting cusp tip. Epithelial proliferation of reduced enamel epithelium, baby monkey. (Mag nification $\mathrm{X} 51$.)

mained in the bony crypt. The boundary of the outer layer of the reduced enamel epithelium had an undulated surface which was of variable thickness and contained many capillaries. The connective tissues overlying the erupting teeth of the baby monkey appeared avascular. Within the reduced enamel epithelium there were sometimes observed areas of a homogeneous material, of ten cresent shaped (Fig. 3). Labeling was occasionally observed in cells surrounding the masses.

The oral epithelium overlying the erupting teeth apparently lost the rete peg arrangement as the tooth moved towards the surface. Although this epithelium appeared thinner than normal, labeled cells were numerous in the basal cell layer of the oral epithelium in the area of the approaching erupting tooth. Increased labeling of the reduced enamel epithelium was not observed during the process of eruption until the reduced enamel epithelium approached contact with the overlying epithelium (Fig. 4).

Just prior to fusion of the two epithelia, there was an increase both in number of labeled cells and thickness of the reduced enamel epithelium (Fig. 5) while the reduced enamel epithelium covering the lateral surfaces of the unerupted crown remained thin, stained lightly, and exhibited no labeling.

Over the occlusal surfaces of the erupting tooth, just prior to eruption, the outer layer of the reduced enamel epithelium exhibited staining comparable in density to the cells of the oral epithelium. The inner layer of the reduced enamel epithelium still could be distinguished as reduced ameloblasts and exhibited no labeling. As contact was established between the oral epithelium and the reduced enamel epithelium, the fused epithelial layer over the erupting cusp tip became compressed into a stratified squamous arrangement (Fig. 6A). At the periphery of the fusion between the basal cell layer of the oral epithelium and the reduced enamel epithelium increased labeling occurred and fingerlike projections extended for short distances along the surface of the reduced enamel epithelium (Fig. $6 \mathrm{~B})$. The epithelial layer over the erupting cusp tip degenerated in its center as the tooth erupted into the oral cavity (Fig. 7). Numerous labeled cells were observed in the 
basal layer of the surface epithelium surrounding the erupting cusp.

At the new sulcus or cleft of the oral epithelium which was produced by, and surrounded the erupting cusp, the immediately adjacent epithelium exhibited characteristics of typical stratified oral epithelium with parakeratosis extending into the shallow gingival sulcus. The free gingival margin at this stage had a rounded appearance. It should be noted that serial sections were studied in order to avoid misrepresentation of the eruption process through inclusion of sections lateral to the erupting cusp tip.

The dento-gingival junction of the recently erupted tooth in the baby monkey presented two morphologically different zones. Coronally from the cemento-enamel junction, zone A, consisted of reduced enamel epithelium, very similar in morphology to the reduced enamel epithelium of the unerupted tooth. A single layer of columnar cells representing reduced ameloblasts were arranged perpendicular to the enamel surface. Separating these reduced ameloblasts from the connective tissue

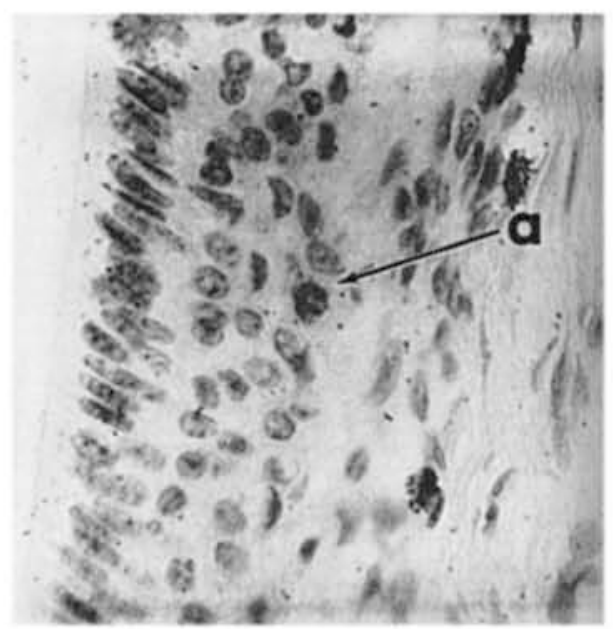

Fig. 8. Solitary labeled cell (a) found in the outer layer of the reduced enamel epithelium of an erupted tooth, baby monkey. (Magnification $\mathrm{X} 700$.

were four-five rows of loosely arranged polygonal cells showing marked variability of nuclear staining (Fig. 9). This zone A (Fig. 1) extended only to the deepest downgrowth of the oral epithelium. In 42 sections containing over 18,000 cells in zone A, only one labeled cell was observed (see Table 1).

TABLE 1

One Hour $\mathrm{H}^{3}$ TDR Radioactive Indices

\begin{tabular}{|c|c|c|c|}
\hline & $\begin{array}{l}\text { Total Cells } \\
\text { Counted }\end{array}$ & $\begin{array}{l}\text { Labeled } \\
\text { Cells }\end{array}$ & $\begin{array}{l}\text { Radioactive } \\
\text { Index }\end{array}$ \\
\hline \multicolumn{4}{|c|}{$\begin{array}{l}\text { Epithelial Attachment } \\
\text { (zone A) }\end{array}$} \\
\hline Baby* & 18256 & 1 & 0.0 \\
\hline Adult** & 1860 & 6 & 0.3 \\
\hline Adult $\mathrm{t}^{* * *}$ & 1142 & 80 & 7.0 \\
\hline \multicolumn{4}{|c|}{$\begin{array}{l}\text { Gingival Sulcus Coronal Part } \\
\text { (zone B) }\end{array}$} \\
\hline Baby & 28614 & 680 & $2: 4$ \\
\hline Adult** & 610 & 30 & 4.9 \\
\hline Adult ${ }^{* * *}$ & 1154 & 72 & 6.2 \\
\hline \multicolumn{4}{|c|}{$\begin{array}{l}\text { Gingival Epithelium } \\
\text { (zone C) }\end{array}$} \\
\hline Baby & 15194 & 305 & 2.0 \\
\hline Adult** & 1404 & 27 & 1.9 \\
\hline Adult*** & 2056 & 75 & 3.6 \\
\hline
\end{tabular}

*Only areas of reduced ameloblasts counted.

${ }^{* *}$ Clinically normal gingiva.

${ }^{* * *}$ Severe gingivitis and beginning periodontitis. 


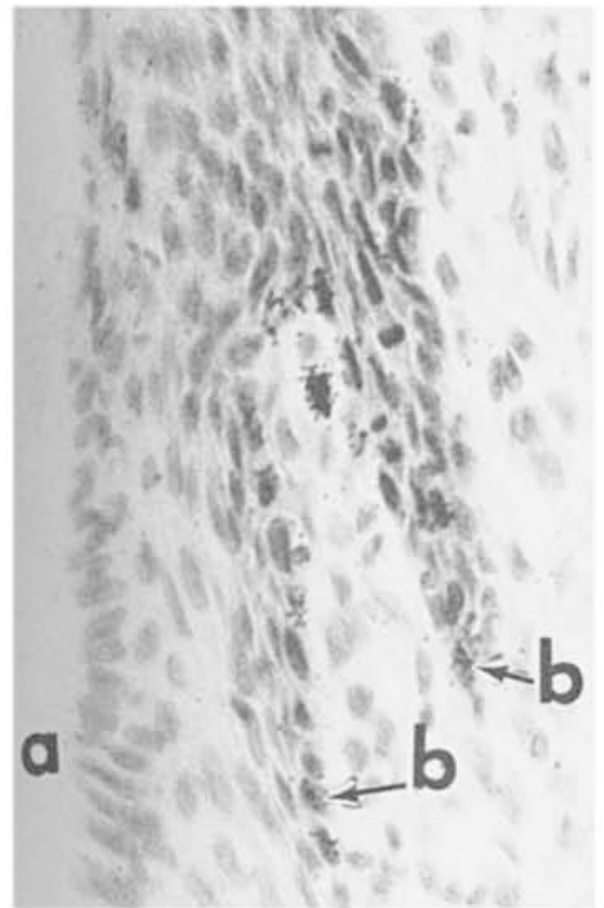

Fig. 9A. Junction of reduced enamel epithelium (a) and sulcus epithelium, baby monkey. Labeled growth. Change in morphology of inner reduced ameloblast layer. (Magnification X550.)

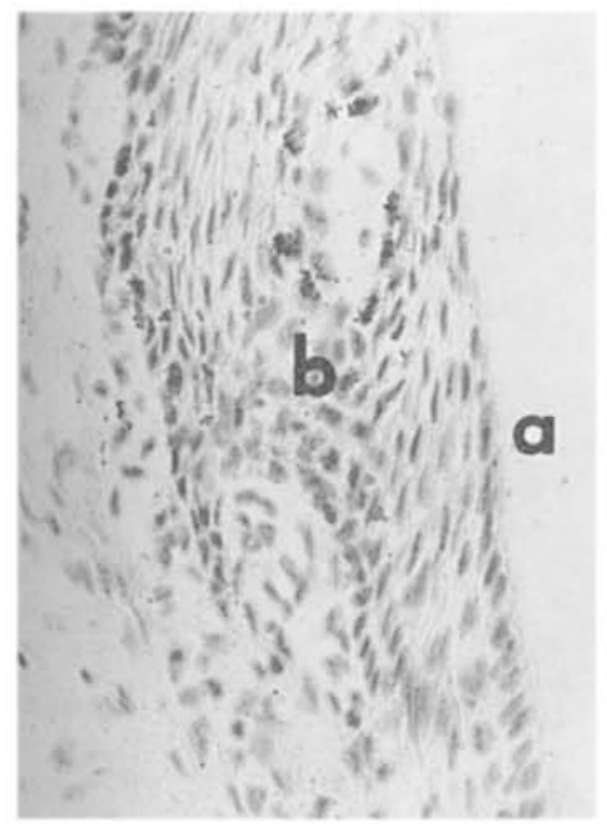

Fig. 9B. Junction of reduced enamel epithelium (a) and sulcus epithelium (b), baby monkey.
Labeled cells at junction. (Magnification X500.)

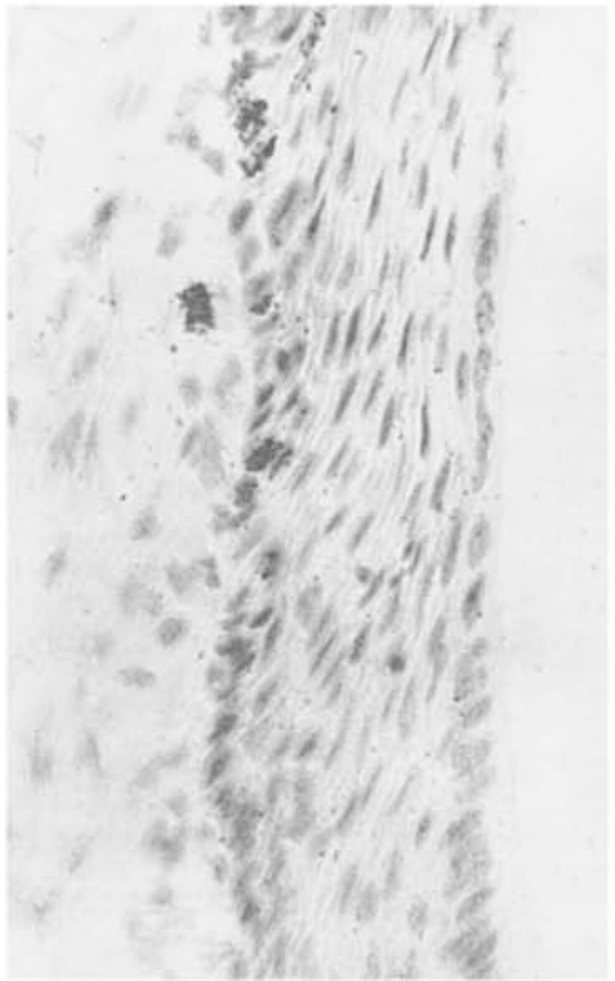

Fig. 9C. Absence of fingerlike projections of epithelium at junction of reduced enamel epi-
thelium and proliferating labeled cells in basal thelium and proliferating la
layer. (Magnigfication X460.)

The coronal zone of the gingival sulcus designated as zone B (Fig. 1) was composed of cells with chromophilia, size, and layering similar to oral epithelium. Zone B of the baby monkey exhibited considerable labeling; 680 labeled cells were counted in a total of 28,614 cells or a mean radioactive index of $2.4 \% \pm 0.4 \%$ for zone B. Individual area indices ranged from 1.2 to $5.1 \%$ in the 42 randomly selected areas of zone $B$. The junction between zone $A$ and zone $\mathrm{B}$ of the sulcus was demarcated by a change in polarity of the inner layer of cells from the columnar perpendicular arrangement of the reduced ameloblasts to a layer of flattened cells parallel to the enamel surface (Figs. 9A, 9B, 9C).

The basal cells in zone B stained more deeply than zone $\mathrm{A}$ and appeared to extend apically on the connective tissue side of the 


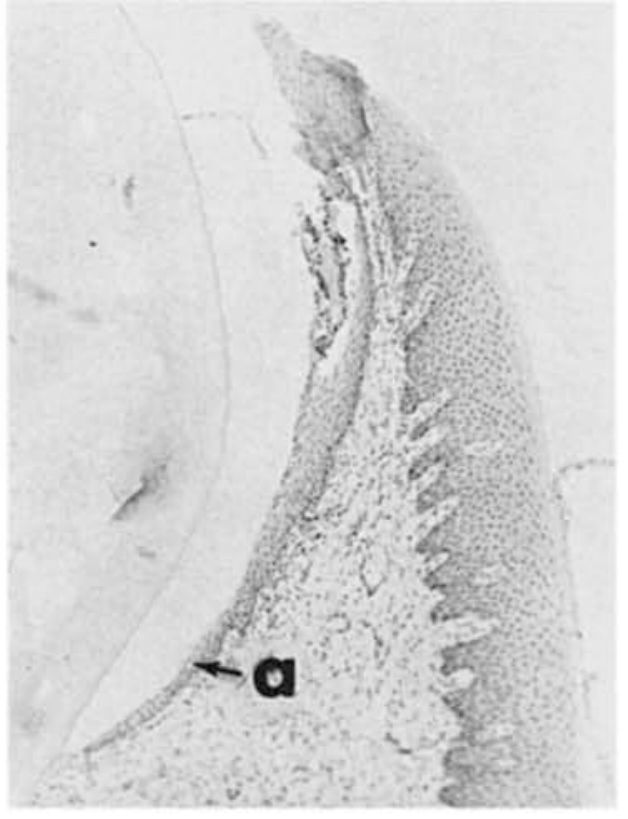

Fig. 10A. Gingival suleus, baby monkey. Reduced enamel epithelium replaced to apical
one-fifth (a) of the sulcus. (Magnitication X80.)

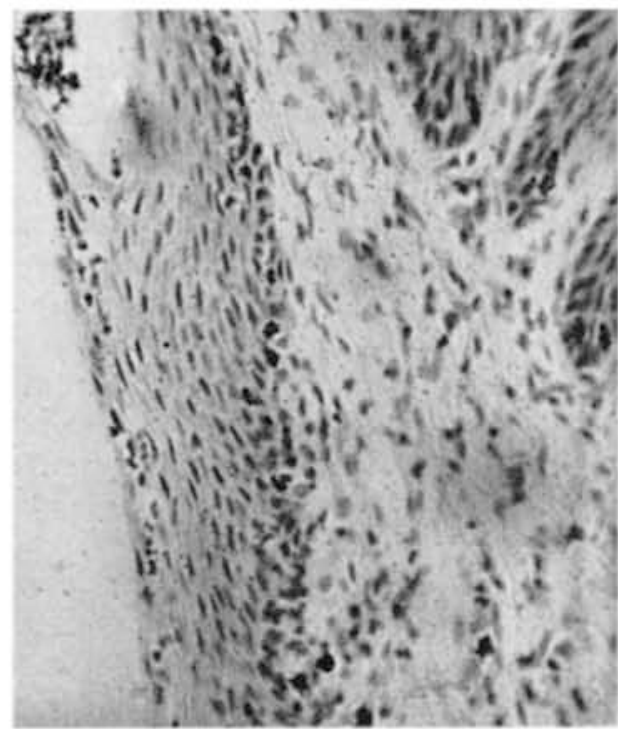

Fig. 10B. Higher magnification of sulcus epi thelium seen in Fig. 10A. and demonstrating epithelium. (Magnification X388.)

outer layer of the reduced enamel epithelium (Figs. 10A, 10B). The apical extension of zone B varied for different teeth and different surfaces of the same tooth.

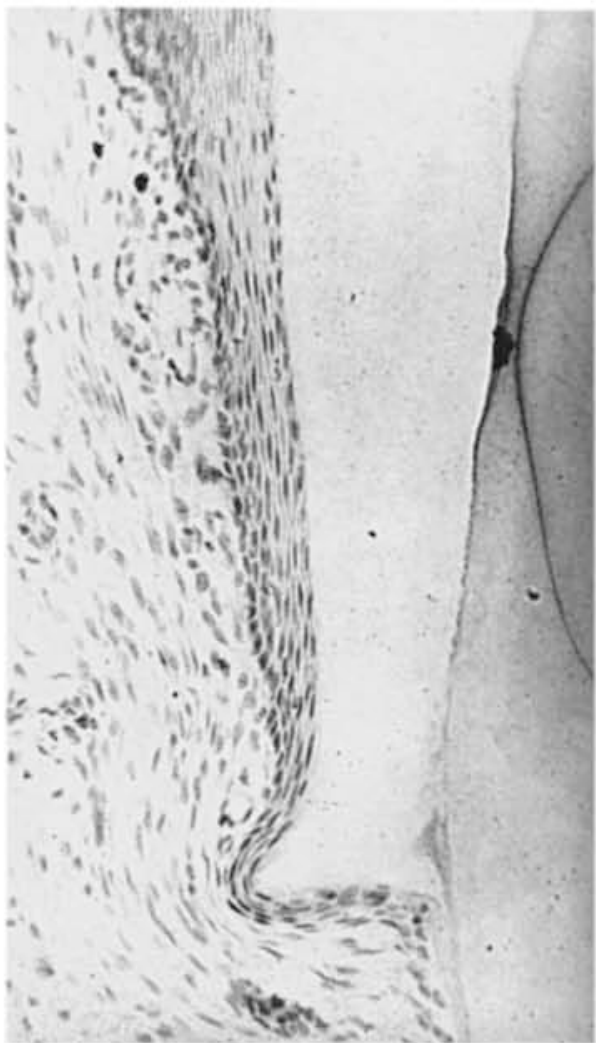

Fig. 11. Apical area of replaced sulcus epithelium, baby monkey. Note similarity in cellu-
lar morphology to Fig. 12B. (Magnification X220.)

An attempt was made to correlate the degree of apical downgrowth of zone B with the sequence of eruption of the deciduous teeth, but no definite relationship could be established, due to variation in downgrowth of oral epithelium on the different surfaces of the same tooth, and to complete replacement of the reduced enamel epithelium by cells having the characteristics of oral epithelium on several recently erupted teeth (Fig. 11). In some intances it appeared like the basal cells of the reduced enamel epithelium started to proliferate and replaced the columnar cells of the original epithelial attachment. It is possible that the replacement of the original attachment is both through downgrowth of oral epithelium and activation and proliferation of the basal cells of the reduced enamel epithelium (Figs. 9A, 9B, 9C). 


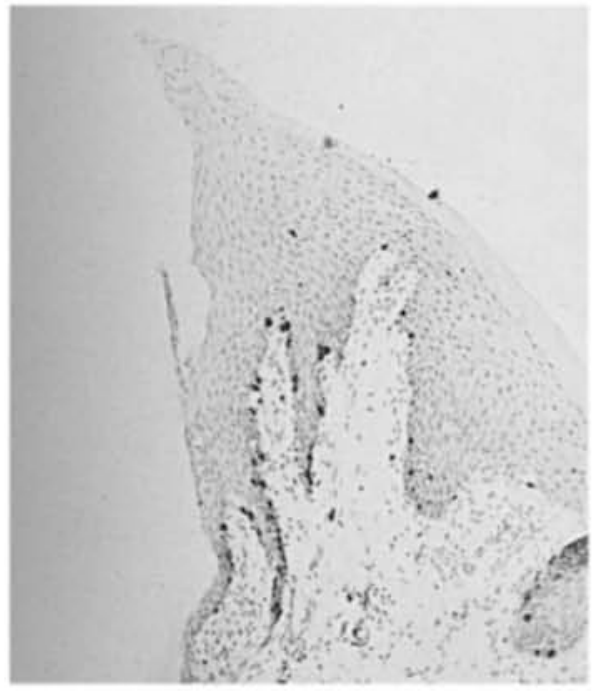

Fig. 12A. Coronal zone of gingival sulcus, adult monkey. Marked labeling in sulcus and ora epithelium. (Magnification X77.)

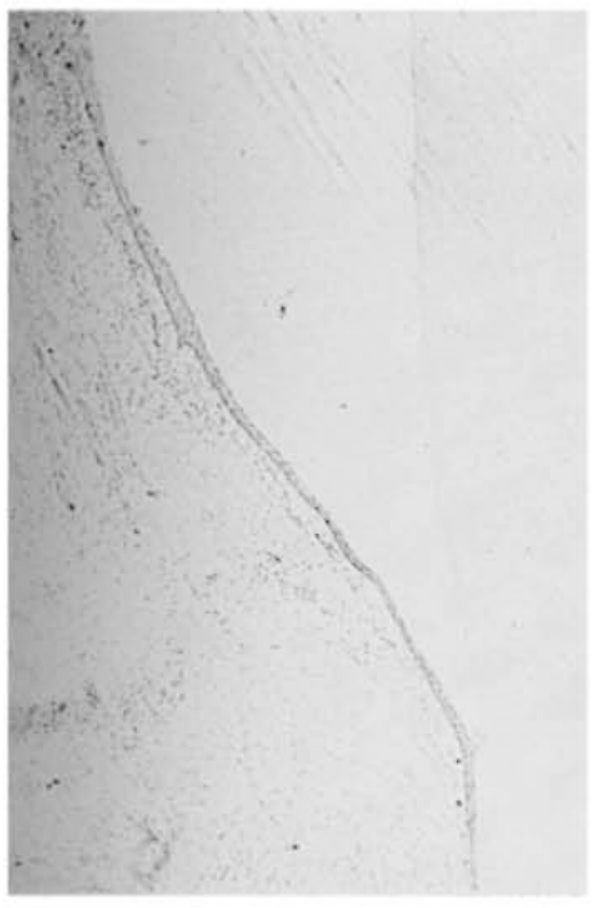

Fig. 12B. Apical zone of gingival sulcus, adult monkey with long thin epithelial attachment. (Magnification X77.)

Although the entire epithelial lining of the gingival sulcus of some of the teeth of the baby monkey was composed of cells having the characteristics of oral epithelium, distinction could be made between two zones: One apical zone comprising a thin epithelial attachment which exhibited labeled cells only occasionally in the basal layer. The second or coronal zone had the characteristic epithelial arrangement and labeling previously described for zone B. As long as reduced enamel epithelium with columnar cells comprised the epithelial attachment of the erupting teeth, no labeled cells could be found in this type of epithelial attachment. However, as soon as a new squamous epithelial attachment was established, either by the downgrowing oral epithelium or by proliferation of basal cells from the reduced enamel epithelium, a few labeled cells could be observed in this zone (Fig. 11).

Numerous labeled cells were observed at the junction of the downgrowing crevicular epithelium and the original epithelial attachment in sections from the baby monkey. In a few sections polymorphonuclear leukocytes were present within the epithelium at the junction between the oral and the reduced enamel epithelium, which might indicate the presence of some irritation in this area.

The gingival epithelium of the baby monkey (zone C) had the typical appearance of well differentiated stratified squamous epithelium with a clearly defined keratin layer and thin rete pegs extending into the underlying connective tissue (Fig. $10 \mathrm{~B})$. The labeling was restricted to the basal and lower spinous layers. A mean radioactivity index of $2 \% \pm .3 \%$ was calculated from individual indices ranging from $.4 \%$ to $4.4 \%$ (see Table 1 ).

B. The Sulcus and Gingival Epithelium of the Adult Rhesus Monkeys. The sulcus epithelium of the adult monkeys appeared similar to that of the baby monkey after the original columnar epithelial attachment had been completely replaced by squamous epithelium (Figs. 12A, 12B, 13, 14). Cell counts performed at zone A (see Table 1) indicated a radioactive index of $0.3 \%$ 


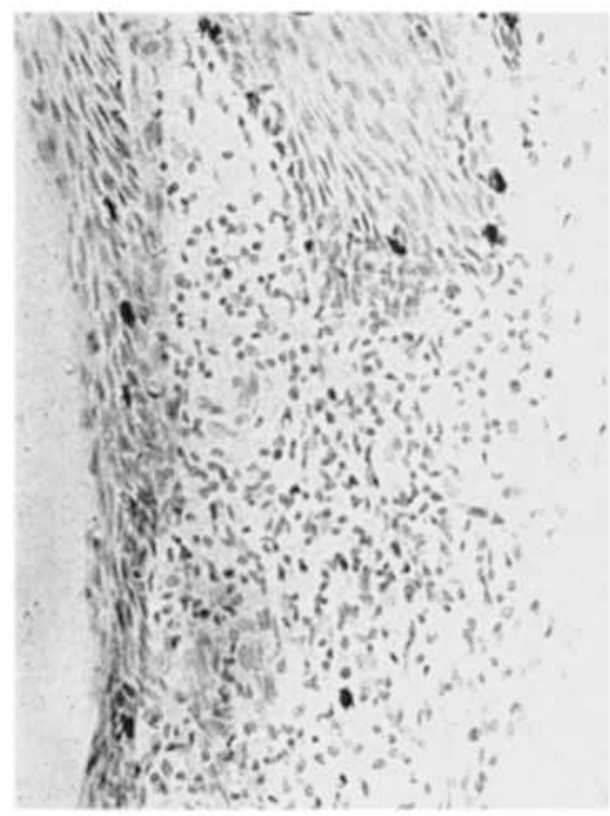

Fig. 13. Junction of coronal and apical zones of sulcular epithelium with inflammation, adult monkey, Labeling of basal and prickle cells. (Magnification X320.)

while zone $\mathrm{B}$ had a radioactive index of $4.9 \%$, and zone $\mathrm{C}$ a mean radioactive index of $3.6 \%$, with individual areas ranging from $.9 \%$ to $6.4 \%$.

Radioautographs from the sulcus epithelium of the pregnant female monkey indicated a high rate of epithelial proliferation associated with marked inflammation (Fig. 15A). The downgrowing sulcus epithelium or epithelial attachment extended apically to the cemento-enamel junction (Fig. $15 \mathrm{~B})$. There was indication of a short epithelial attachment, less than $1 \mathrm{~mm}$. in length, but this zone showed a high degree of mitotic activity of the epithelium associated with an extension of severe gingival inflammation adjacent to the epithelial attachment (Fig. 15B). The thin extension of the sulcular epithelium that in this instance apparently served as an epithelial attachment had a radioactive index of $7 \%$ while the mean radioactive index of the coronal part of the sulcus epithelium was $6.2 \%$. The increased rate of epithelial proliferation associated with inflammation and downgrowth of the epithelial attachment

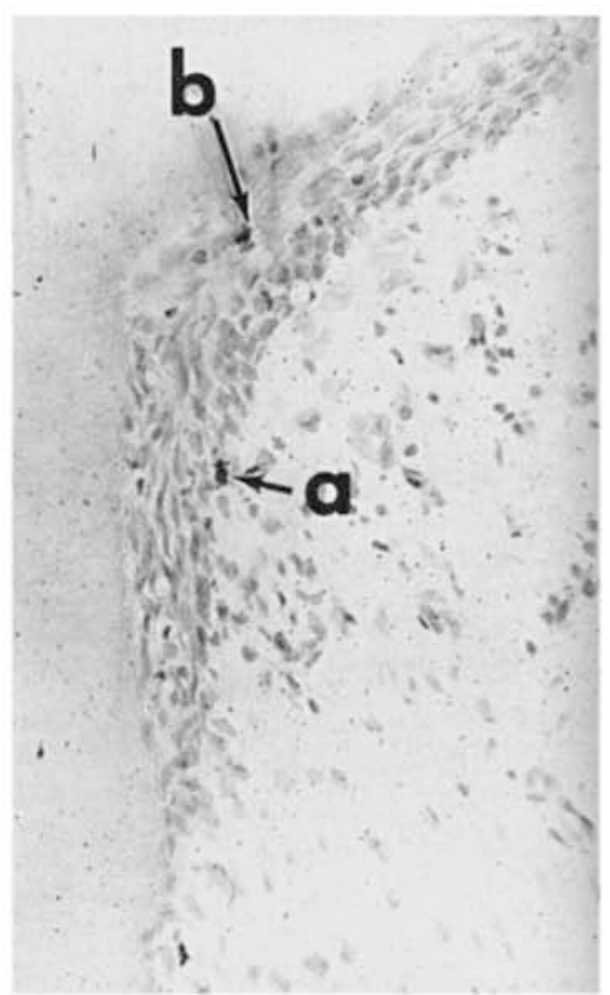

Fir. 14. Labeled cell in basal layer (a) and (b) in prickle cell layer of epithelial attachment (Magnification X320.)

represents the process of destructive periodontal disease with beginning pocket formation. There were also marked proliferative activity in the interproximal "Col" area (Fig. 16).

Several of the adult monkeys in our monkey colony have periodontitis with pocket formation of moderate depth associated with calculus and severe gingival inflammation.

\section{DISCUSSION AND SIGNIFICANCE OF FINDINGS}

The development and mitotic behavior of the epithelial attachment in rhesus monkeys has been described from beginning of amelogenesis in the fetal life through eruption of deciduous teeth in a baby monkey and establishment of a physiologic mature epithelial attachment in the fully erupted deciduous teeth. Then the gingival sulcus of an adult monkey with minimal gingival 


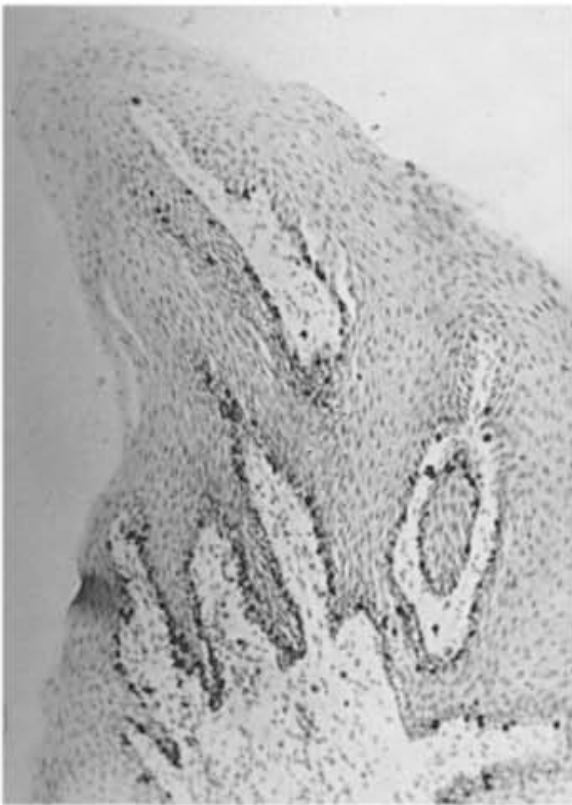

Fig. 15A. Coronal zone of sulcus epithelium of of gingival and sulcus epithelium. (Magnification X133.)

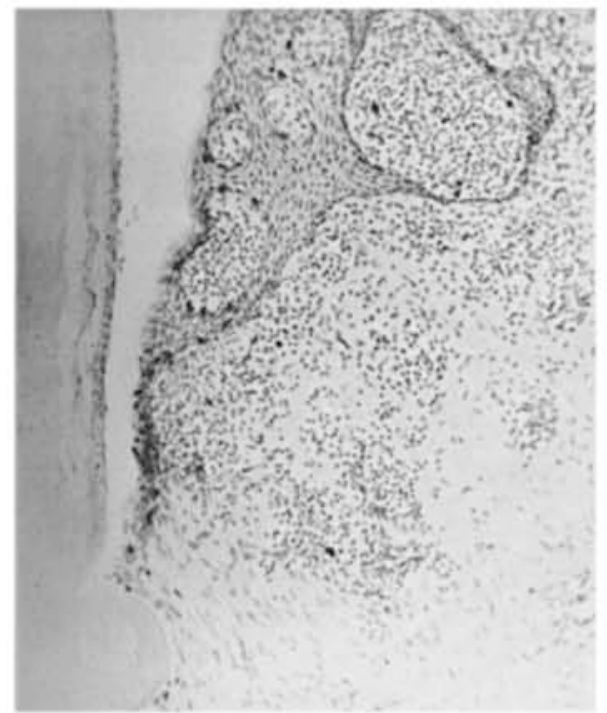

Fig. 15B. Apical zone of sulcus epithelium of pregnant monkey demonstrating marked labeling extending to base of sulcus. (Magnification ing ex

inflammation was studied, and finally the mitotic activity related to epithelial downgrowth associated with active destructive periodontal disease was presented.

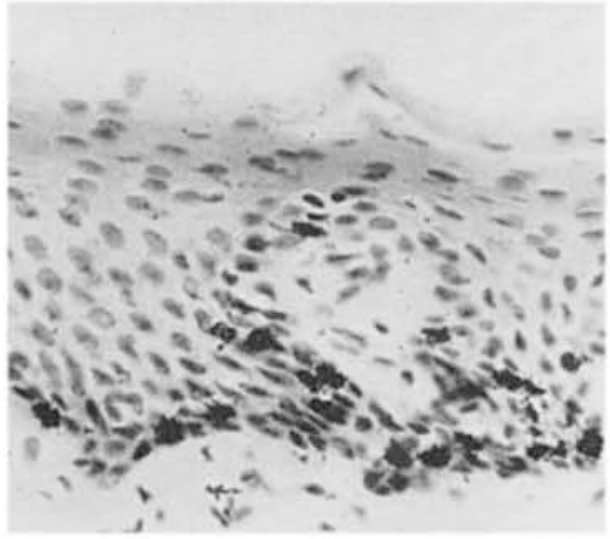

Fig. 16. Non-keratinized interproximal "Col" area of pregnant monkey. Labeled cells in basal area of pregnant monkey. Labeled cells in
layer of epithelium. (Magnification X620.)

The derivation of the cells from the enamel organ which participate in the formation of the reduced enamel epithelium is somewhat controversial and may depend to a certain extent on the species of the animals. ${ }^{2,3,4,25,26,27,28}$ Previous reports from studies of rhesus monkeys have indicated that residual cells of all parts of the enamel organs participate in the formation of the reduced enamel epithelium. ${ }^{3,28,29}$ Gottlieb ${ }^{2}$ claimed that in humans, the stellate reticulum and the stratum intermedium undergo atrophy prior to eruption and leave the outer enamel epithelium to form the outer layer of the reduced enamel epithelium, while Ussing ${ }^{27}$ felt that the outer layer of the reduced enamel epithelium is derived from the stratum intermedium and perhaps includes some cells from the outer enamel epithelium. In the present study stellate reticulum cells could not be identified following advanced amelogenesis. The outer layer of the reduced enamel epithelium appeared to be composed of cells derived from the stratum intermedium and the outer layer of enamel epithelium. It was remarkable how the ameloblasts retained a columnar appearance following completion of amelogenesis and later as part of the reduced enamel epithelium (Figs. 6, $10)$. These cells, however, changed in appearance and positioning of the nucleus from the active enamel forming ameloblasts to the inactive reduced ameloblasts, that 
formed the inner layer of the reduced enamel epithelium.

The reduced enamel epithelium did not appear to be as active during the process of eruption as had been previously reported. 3, 28,29 Labeled cells were very seldom observed in the reduced enamel epithelium until the tooth during eruption approached the oral epithelium. Projections from the oral epithelium into the underlying connective tissue were not seen in the zone of eruption. The oral epithelium exhibited a passiveness to the process of eruption similar to that described by Uohara $^{25}$ in the rat. Proliferation of the outer layer of the reduced enamel epithelium did not occur either until the reduced epithelium came in close proximity to the basal layer of the oral epithelium (Figs. $4,5)$. The reason for stimulation and proliferation of the reduced enamel epithelium at that particular stage remains unexplained.

The epithelial attachment of the erupting tooth differed greatly from the epithelial attachment of the fully erupted and functional tooth. The reduced ameloblasts that made up at least part of the epithelial attachment during eruption did not exhibit any labeling. The lack of mitotic activity in this part of the reduced enamel epithelium suggest that these cells are quiescent. This may indicate that they are protected from oral stimuli by an organic attachment to the enamel surface. However, as the tooth erupted fully, these cells were replaced by cells of a regular squamous character (Fig. 10) morphologically identical to the oral epithelium. These new or altered cells were closely adapted to the tooth surface and apparently functioned as an epithelial seal or "attachment." They also exhibited some mitotic activity which conforms to the concept of an adhering dynamic epithelial cuff rather than a fixed organic union of stationary cells comprising an epithelial attachment to an enamel cuticle.

It does appear, at least in rhesus monkeys, that Gottlieb's ${ }^{2}$ concept of an organic epithelial attachment may be valid, but this attachment is of a transient nature. It constitutes a protective mechanism for penetration of bacteria and bacterial toxins until the tooth has erupted fully and the dynamics of the normal self-cleansing shallow gingival crevice has been established. ${ }^{30}$

From that time there appears to be an epithelial adhesion rather than an attachment in Gottlieb's sense of the word. The cells of the coronal zone of the gingival crevice were observed to proliferate apically on the connective tissue side of the reduced enamel epithelium during the eruption of the teeth. At the junction of the downgrowing epithelium and the reduced enamel epithelium, a number of labeled cells were observed (Figs. 7, 10, 11, 12). Whether these proliferating cells originate from the coronal zone of oral epithelium as proposed by Becks ${ }^{31}$ and Baume 28,29 or they represent proliferating cells from the outer layer of the reduced enamel epithelium, combined with cells of the coronal zone, as proposed by $\mathrm{McHugh},{ }^{3}$ cannot be determined from our study. However, it was found that the cells of the outer layer of the reduced enamel epithelium do have proliferative potentials when they are adequately stimulated. This was observed when the outer layer of reduced enamel epithelium approached the oral epithelium at the time of eruption. At that time the reduced enamel epithelium increased in thickness and exhibited considerable labeling (Fig. 5).

The replacement of the original epithelial attachment by a renewing cell population derived from the oral epithelium, and possibly in part from the outer layer of the reduced enamel epithelium, takes place quite rapidly as the tooth erupts into function. In the four and one-half month baby monkey, the epithelial lining of the total gingival crevice including the epithelial attachment, was replaced completely by normal functional stratified squamous epithelium in most of the fully erupted functional deciduous teeth.

The sulcus epithelium and the epithelial 
attachment of the functioning teeth of the baby monkey and of the adult male monkey with healthy gingival tissues were remarkably similar, both in appearance and labeling. Labeled cells were observed in the basal layer of each of the three zones, consistent with the concept of an adhering epithelial cuff composed of a renewing cell population.

The significantly lower mitotic activity in the zone of the epithelial attachment (zone A, Table 1) compared to zone B in normal gingival tissues indicates a sealing effect of the epithelial attachment from the rest of the gingival sulcus (zone $B$ ).

It appears that in destructive periodontal disease the epithelial attachment or cuff has lost its ability to seal the bottom of the sulcus and to prevent penetration of bacterial products into the underlying tissues. This is evident by the markedly increased proliferative activity of the cells of the epithelial attachment compared with the normal relatively quiescent zone of a sealing epithelial attachment. The inflammatory reaction and increased rate of mitosis in active periodontal disease constitutes evidence of spread of irritants into tissues that normally are protected by the physiologic dynamic epithelial attachment.

The findings from this study indicate that the reduced enamel epithelium does not persist as "a locus minoris resistentiae," following normal eruption of teeth.

\section{SUMMARY}

The origin and behavior of the epithelial attachment and the cells lining the gingival sulcus have been studied in a fetus, a baby, and two adult rhesus monkeys. Following completion of amelogenesis, the reduced enamel epithelium exhibits only very slight proliferative activity on the outer surface and no mitotic activity of the reduced ameloblasts at any time.

As the tooth approaches the oral epithelium during eruption, proliferation is initiated on the outer surface of the reduced enamel epithelium, at the tip of the erupt- ing cusp, until this epithelium fuses with the oral epithelium.

From the beginning of the eruption into the oral cavity, to the completion of the eruption, part of the epithelial attachment is made up of reduced ameloblasts with no proliferative activity. The reduced enamel epithelium is gradually replaced by squamous epithelium resembling oral epithelium as the tooth erupts into functional occlusion and at that time the dynamics of a normal functional epithelial attachment is established.

The normal gingival sulcus and epithelial attachment in fully erupted functional teeth appeared and behaved identical for the deciduous teeth of the baby monkey and the permanent teeth of the adult monkey.

In destructive periodontal disease, the markedly increased proliferation of the cells of the epithelial attachment indicated a change of functional behavior of these cells due to change in environment.

\section{CONCLUSIONS}

1. In rhesus monkeys there is a transient and partial epithelial attachment of reduced enamel epithelium until the tooth is fully erupted.

2. The original epithelial attachment is replaced gradually by an epithelial cuff of squamous cells. This replacement is completed approximately at the time the tooth is fully erupted and functioning.

3. The presence of mitotic activity in the epithelial attachment of fully erupted deciduous and permanent teeth support the concept of a dynamic mechanism of epithelial adhesion and a self cleansing gingival sulcus rather than a static organic epithelial attachment.

4. The physiologic seal of the normal epithelial attachment is indicated by much less mitotic activity in the zone of epithelial attachment than in the rest of the gingival sulcus. 
5. In destructive periodontal disease there is a marked increase in proliferation of the cells of the epithelial attachment indicating lack of seal or protection from environmental irritants.

6. The reduced enamel epithelium in monkeys does not persist after eruption to form "a locus minoris resistentiae" for periodontal disease.

\section{ACKNOWLEDGEMENT}

We would like to express our acknowledgment to Miss Joan E. Wilhelm who prepared all the radioautographs and to Mr. Charles T. Knorpp, M.S. Assistant Chief Radioisotope Unit, for his technical assistance. Both from the Veterans Administration Hospital, Ann Arbor, Michigan.

\section{BIBIIOGRAPHY}

1. Waerhaug, J. The gingival pocket. Odont. Tskr., 60:1, Suppl. 1, 1952.

2. Gotrlieb, B. Der Epithelansatz am Zahne. Dtsch. M. Schr. f. Zhanh., 39:142, 1921.

3. McHugh, W. D. The development of the gingival epithelium in the monkey. Dent. Pract. and Dent. Rec., 11:314, 1961.

4. Hunt, A. M., and Paynter, K. J. The role of cells of the stratum intermedium in the development of the guinea pig molar. A study of cell differentiation and migration using tritiated thymidine. Arch. Oral Biol., 8:65, 1963.

5. Greulich, R. C. Epithelial DNA and RNA synthetic activities of the gingival margin. Abstr. J. Dent. Res., 40:682, 1961.

6. Beagrie, G. S., and Skougaard, M. R. Obser vations on the life cycle of the gingival epithelial cells of mice as revealed by autoradiography. Acta. Odont. Scandinav., 20:15, 1962.

7. Skougaard, M. R., and Beagrie, G. S. The renewal of gingival epithelium in marmosets (callithrix jacchus) as dtermined through autoradiography with thymidine $\mathrm{H}^{3}$. Acta. Odont. Scandinav., $20: 467,1962$.

8. Dimassimo, C. Proliferation and migration of cells in the gingival epithelium. Eastman Dental Dispensary, 1963, iii +58 p. Typed thesis.

9. Schultz-Haudt, S. D., and From, S. Dynamics of periodontal tissues. I. The epithelium. Odont. Tskr., 69:431, 1961 .

10. Cohen, B. Pathology of the interdental tissues. Dent. Pract. and Dent. Rec., 9:167, 1959.

11. Fish, Wilfred. Etiology and prevention of periodontal breakdown. D. Progress, 1:234, 1961 .
12. Melcher, A. H. Lesions of the interdental gingival septum and their effect on therapeutic procedures. J. Periodont., 33:311, 1962.

13. Hughes, W. L., et al. Cellular proliferation in the mouse as revealed by autoradiography with tritiated thymidine. Nat. Acad. Sci, U. S. Proc., $44: 476,1958$.

14. Bollum, F., and Potrer, V. Incorporation of thymidine into deoxyribonucleic acid by enzymes from rat tissues. J. Biol. Chem., 233-478, 1958.

15. Cronkite, E. P., et al. The use of tritiated thymidine in the study of DNA synthesis and cell turnover in hemopoietic tissues. Lab. Invest., $8: 263$, 1959.

16. Pelc, S. R. On the question of renewal of differentiated cells. Expl. Cell Res., 29:194, 1963.

17. Starkey, W. E. The migration and renewal of tritium labeled cells in the developing enamel organ of rabbits. Brit. Dent. J., 115:143, 1963.

18. Owen, M., and Macpherson, S. Cell population kinetics of an osteogenic tissue, II. USAEC Report BNL-6738, Brookhaven National Laboratory, 1963.

19. Greulich, R. C. Cell proliferation and $\mathrm{mi}-$ gration in the epithelial attachment collar of the mouse molar. Abstr. Internat. A. Dent. Res., 40:80, 1962.

20. Messier, B., and Leblond, C. P. Preparation of coated radioautographs by dipping sections in fluid emulsion. Soc. Exper. Biol. Med. Proc., 96:7, 1957.

21. Joftes, David. Liquid emulsion in autoradiography with tritium. Lab. Invest., 8:131, 1959.

22. Messier, B., and Leblond, C. P. Cell proliferation and migration as revealed by radioautography after injection of thymidine $\mathrm{H}^{3}$ into male rats and mice. Am. J. Anat., 106:247, 1960.

23. Engler, W. O., Ramfjord, S. P., and Hiniker, J. J. Mitotic potential of the enamel organ of the rhesus monkey. In press.

24. Hwang, W. S., Tonna, E. A., and Cronkite, E. P. An autoradiographic analysis of the cellular growth of mouse incisors using tritiated thymidine. Abstr. Internat. A. Dent. Res., 1963, abstract 141.

25. Uohara, G. I. Histogenesis of the gingival sulcus epithelium in the rat. J. Period., 30:326, 1959.

26. Johnson, P. L., and Bevelander, G. The role of the stratum intermedium in tooth development. Oral Surg., Oral Med., and Oral Path., 10:437, 1957.

27. Ussing, M. J. The development of the epithelial attachment. Acta. Odont. Scandinav., 13:123, 1955 .

28. Baume, L. J. Observations concerning the 
histogenesis of the epithelial attachment. J. Period., $23: 71,1952$.

29. Baume, L. J. The structure of the epithelial attachment revealed by phase contrast microscopy. J. Period., 24:99, 1953.
30. Brill, N. The gingival pocket fluid. Acta. Odont. Scandinav., 20:1, Suppl. 32, 1962.

31. Becks, H. Normal and pathologic pocket formation. J.A.D.A., 16:2167, 1929.

\section{Bone Swaging}

BY SOL J. EWEN, D.D.s., NEW YORK, NEW YORK

$\mathrm{T}$

HE swaging of bony protuberances following extractions and alveolectomies is a familiar procedure to the oral surgeon. When such prominences occur following a surgical procedure, the operator employs a bone swaging tap, the tip of which is serrated. With mallet blows the tap is directed against the bony prominence and the surgeon is able to mold the bone and contour it to shape without resorting to incision or surgical intervention (Fig. 1).

To familiarize himself with the procedure the author applied a woodstick to a recent extraction bone ledge (Fig. 2a and b). Following several short mallet blows the buccal aspect of the ledge was modified so that along with healing a satisfactory contour resulted (Fig. 2c). Having found the method effective, bone swaging was adopted as one technic in the treatment procedures for periodontal disease. Since

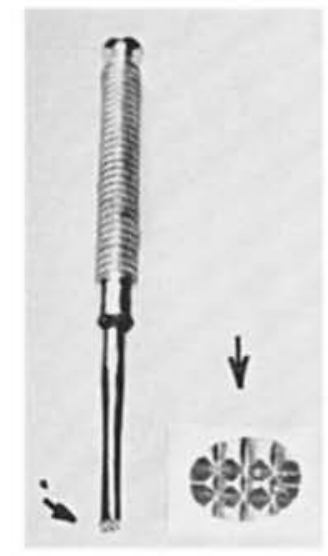

Fig. 1. Bone swager with serrated tip (large arrow).

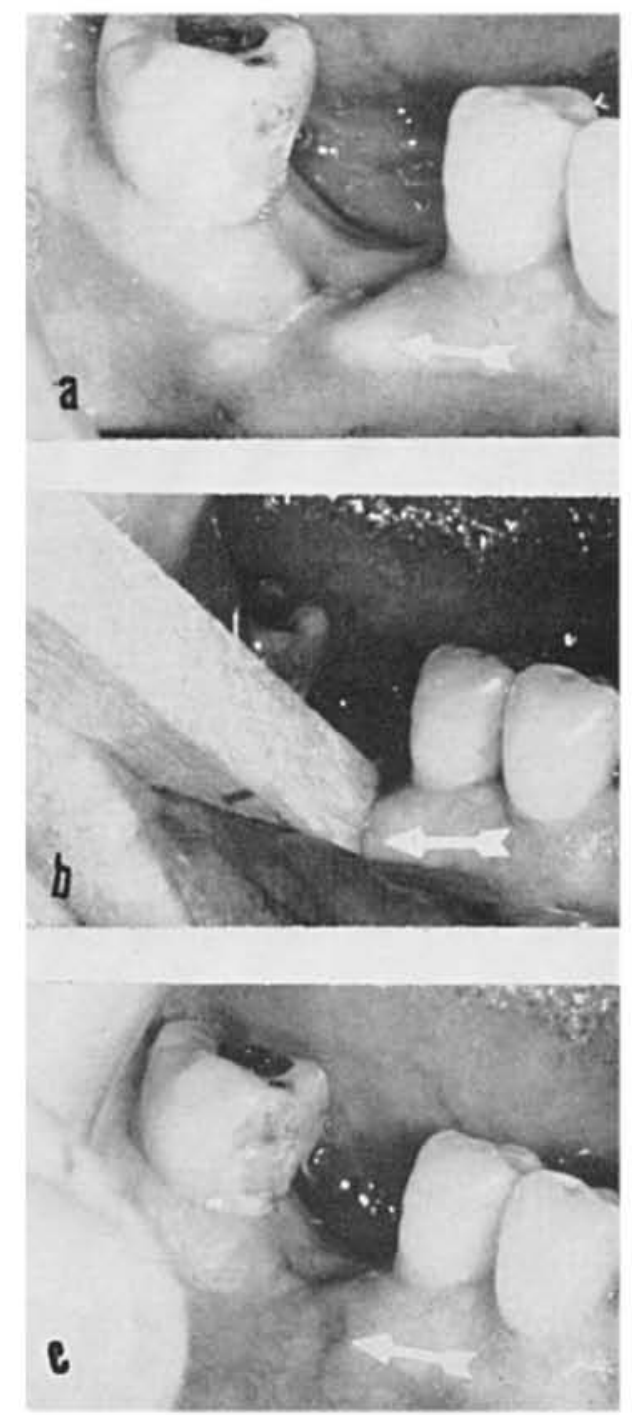

Fig. 2. (a) Bone ledge remains after extraction. (b) $\mathrm{A}$ woodstick is malleted against the ledge. (c) Bone and gingival contour appear flattened 